\title{
Idarucizumab for a traumatic head injury patient taking dabigatran
}

\author{
Shuhei Maruyama ${ }^{1 *}$, Koichi Hayakawa', Shuji Kanayama', Hiromu Iwamura', Daiki Wada', Fukuki Saito',
} Yasushi Nakamori ${ }^{1}$ and Yasuyuki Kuwagata ${ }^{2}$

\begin{abstract}
Background: Dabigatran is one of the four drugs currently used as a direct oral anticoagulant in Japan. Idarucizumab, which specifically targets dabigatran, was recently approved in Japan. We present a case of intracranial hemorrhage in a traumatic brain injury patient taking dabigatran who was treated by administering idarucizumab.

Case presentation: A 72-year-old man was injured in a traffic accident and was transferred to our emergency room. On arrival, his Glasgow Coma Scale score was 14 (eye, 3; verbal, 5; motor, 6), and his other vital signs were stable. Computed tomography $(\mathrm{CT})$ imaging on arrival showed a small intracranial hematoma. A second $\mathrm{CT}$ $3 \mathrm{~h}$ later revealed expansion of the hematoma. We received information that he was taking dabigatran only after the second CT. Idarucizumab was then promptly administered, and emergency craniotomy for hematoma removal was performed. There was no tendency for bleeding during the operation, and blood transfusion was not required during the perioperative period. Although the patient underwent additional surgery for subdural effusion and hydrocephalus, his postoperative course was uneventful. He was transferred to a rehabilitation hospital on postoperative day 102.
\end{abstract}

Conclusion: We managed a patient taking dabigatran who suffered traumatic intracranial hemorrhage by administering idarucizumab preoperatively without the need for blood transfusion perioperatively. We suggest that idarucizumab could be a potent therapeutic bridge to definitive surgical management in such patients with traumatic brain injury who are taking dabigatran.

Keywords: Dabigatran, Direct oral anticoagulants, Idarucizumab, Specific neutralizing drug, Traumatic brain injury, Traumatic intracranial hemorrhage

\section{Background}

As the population ages, more people are likely to be on anticoagulant drugs due to the higher prevalence of atrial fibrillation or valvular surgery [1,2]. Direct oral anticoagulants (DOAC) have a favorable benefit-risk profile compared with vitamin $\mathrm{K}$ antagonists and are associated with similar or better outcomes in cases of major bleeding and urgent procedures [3-5]. A study of intracranial bleeding due to blunt trauma in patients taking anticoagulants showed that the mortality and surgical intervention rates were significantly lower in the group receiving DOAC than in the warfarin group [6].

\footnotetext{
* Correspondence: suugakunotiti@yahoo.co.jp

${ }^{1}$ Department of Emergency and Critical Care Medicine, Kansai Medical University Medical Center, 10-15 Fumizono-cho, Moriguchi, Osaka 570-8507, Japan

Full list of author information is available at the end of the article
}

Acute traumatic coagulopathy can sometimes occur in head trauma patients, thus making it difficult to complete the surgery and highlighting the importance of the careful management of the coagulation system [7].

Idarucizumab is a humanized monoclonal antibody fragment that binds dabigatran with high affinity and specificity and rapidly reverses its anticoagulant activity. We present the case of a patient with severe traumatic brain injury taking dabigatran whom we treated with the administration of idarucizumab and craniotomy for hematoma removal.

\section{Case presentation}

A 72-year-old man was injured when the bicycle he was riding collided with a car (we estimated that the time of injury was $4 \mathrm{~h}$ after the last taking of dabigatran). On hospital arrival, his Glasgow Coma 
Table 1 Results of arterial blood gas analysis and blood tests on arrival

\begin{tabular}{llll}
\hline Arterial blood gas findings & Blood test findings & \\
\hline $\mathrm{pH}$ & 7.462 & PT & $30 \%$ \\
$\mathrm{PaO}_{2}$ & $242 \mathrm{mmHg}$ & aPTT & $94.9 \mathrm{~s}$ \\
$\mathrm{PaCO}_{2}$ & $33.7 \mathrm{mmHg}$ & FDP D-dimer & $12.8 \mu \mathrm{g} / \mathrm{mL}$ \\
Base excess & $0.4 \mathrm{mmol} / \mathrm{L}$ & $\mathrm{Hb}$ & $12.3 \mathrm{~g} / \mathrm{dL}$ \\
Lactate & $13 \mathrm{mg} / \mathrm{dL}$ & Platelets & $199 \times 10^{3} / \mathrm{\mu L}$ \\
& & Blood urea nitrogen & $24 \mathrm{mg} / \mathrm{dL}$ \\
& & Serum creatinine & $1.2 \mathrm{mg} / \mathrm{dL}$ \\
& & Creatinine clearance & $47 \mathrm{~mL} / \mathrm{min}$ \\
\hline
\end{tabular}

Scale (GCS) score was 14 (eyes, 3; verbal, 5; motor, 6), and his vital signs were stable.

Arterial blood gas analysis results while receiving oxygen by reservoir mask at a rate of $8 \mathrm{~L} / \mathrm{min}$ and blood test findings are shown in Table 1. Whole-body computed tomography (CT) showed a right temporal lobe contusion, acute subdural hematoma, zygomatic bone fracture, and third lumbar compression fracture. A representative head CT image is shown in Fig. 1.

We planned a follow-up CT $3 \mathrm{~h}$ later and observed him carefully in the intensive care unit. The second CT showed that the temporal lobe hematoma had increased to $80 \times 80 \times 40 \mathrm{~mm}$ (Fig. 2). At this time $(7.5 \mathrm{~h}$ after the last taking of dabigatran), his GCS score was 13 (eyes, 3; verbal, 4; motor, 6) and manual muscle test results of $3 / 5$ degrees indicated left hemiplegia. We decided to perform an emergency craniotomy for hematoma removal. At this time, we were informed of

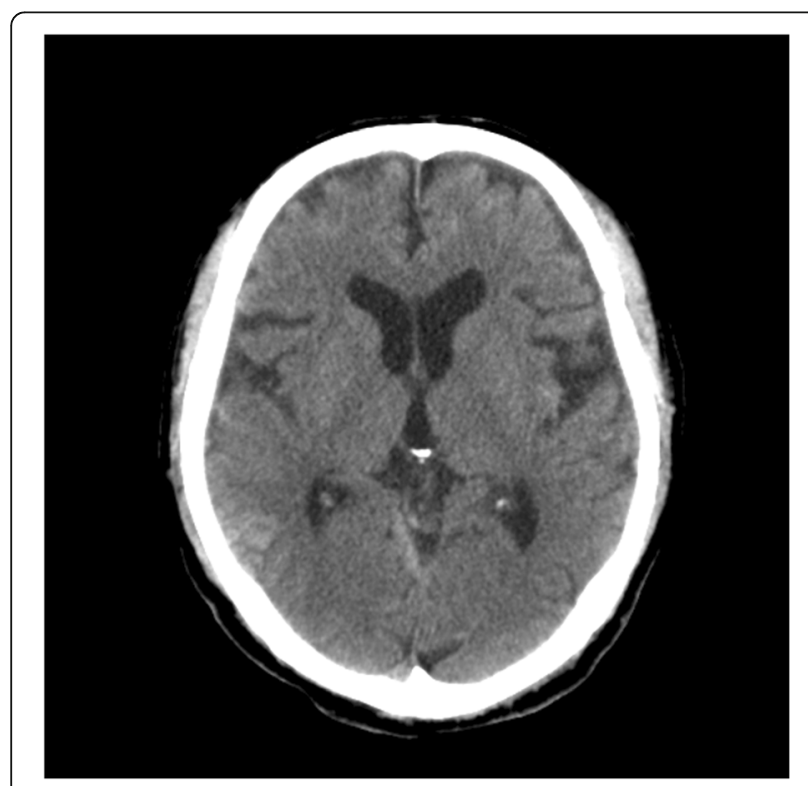

Fig. 1 Head CT on admission showed a right temporal lobe contusion and subdural hematoma in the cerebellum tent

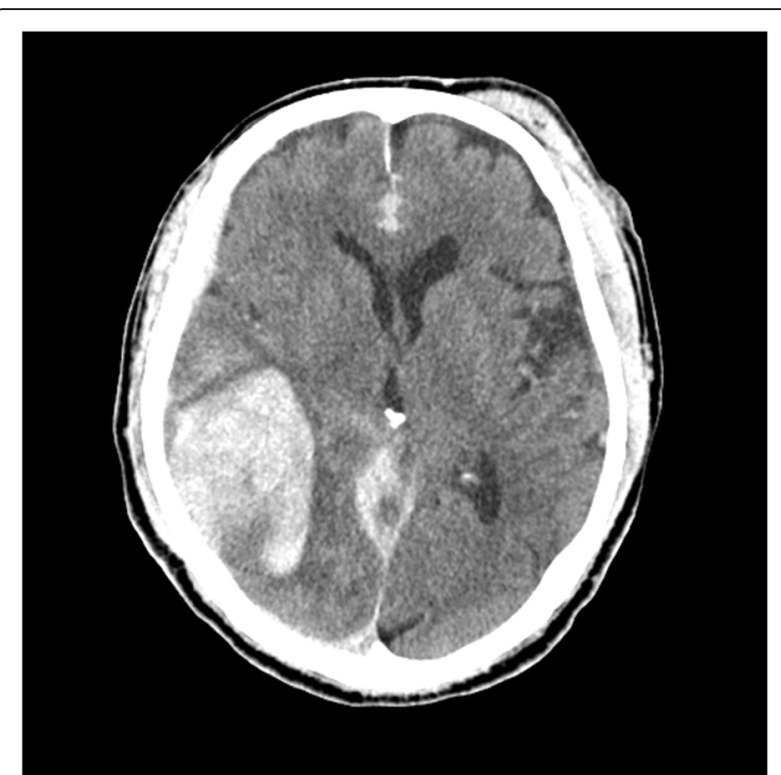

Fig. 2 Head CT $3 \mathrm{~h}$ after admission showed the expansion of the temporal lobe hematoma

his medical history and daily prescriptions by his primary care hospital.

His past medical history included atrial fibrillation, and his daily prescriptions included dabigatran $220 \mathrm{mg}$. Immediately after learning this, we administered $5 \mathrm{~g}$ of idarucizumab by intravenous injection at $5.5 \mathrm{~h}$ after the injury ( $9.5 \mathrm{~h}$ after the last taking of dabigatran), and the craniotomy was begun at $6.5 \mathrm{~h}$ after the injury. There was no bleeding tendency during surgery, no blood

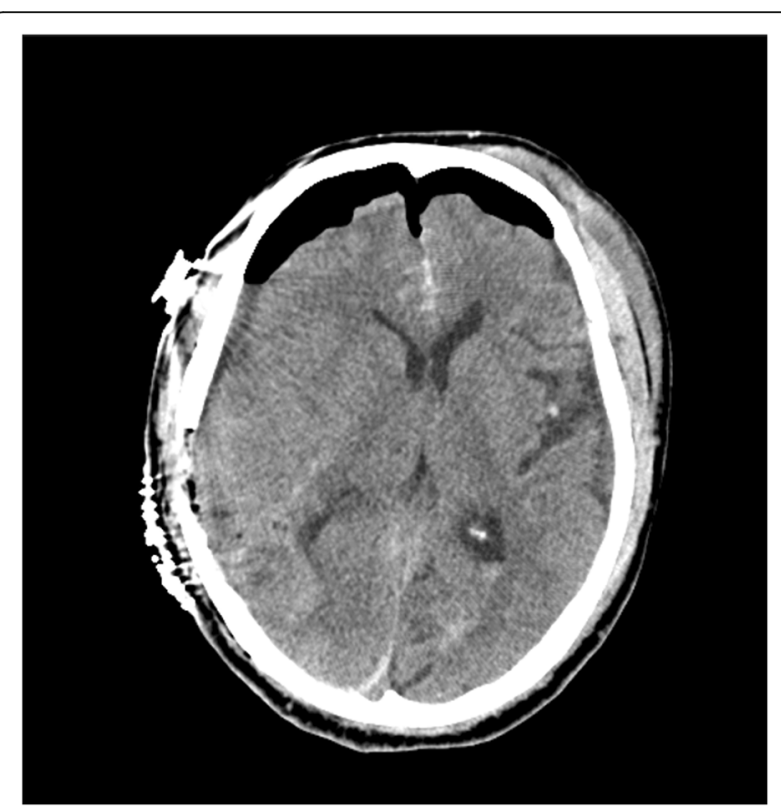

Fig. 3 Head CT after surgery showed the removal of the hematoma 


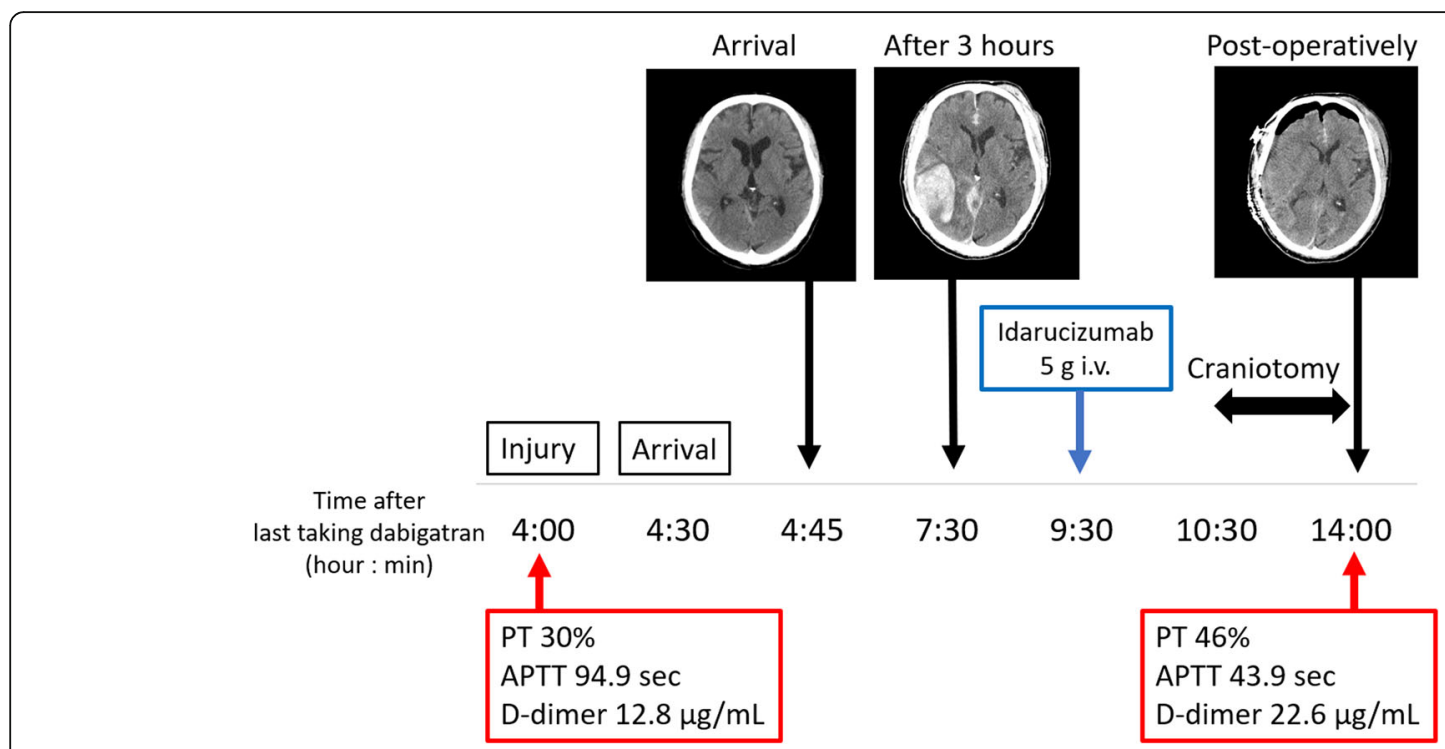

Fig. 4 Clinical course, laboratory data, and head CT images

transfusions were required, and the amount of bleeding was small.

After the surgery, the CT findings revealed that the intracranial hematoma had been removed (Fig. 3), and blood test findings were PT 46\%, aPTT 43.9 s, and FDP D-dimer $22.6 \mu \mathrm{g} / \mathrm{mL}$. The clinical course, laboratory data, and head CT images are shown in Fig. 4. We resumed his dabigatran on postoperative day (POD) 7. A ventriculoperitoneal shunt operation was performed for hydrocephalus on POD 47. He was transferred to a rehabilitation hospital with a Glasgow Outcome Scale score of 3 on POD 102.

\section{Discussion}

Idarucizumab is a humanized monoclonal antibody fragment that binds dabigatran with 350-fold higher affinity than that of dabigatran for thrombin and rapidly reverses its anticoagulant activity. Guidelines for the use of idarucizumab include life-threatening bleeding, bleeding into a critical organ or closed space, prolonged bleeding despite local hemostatic measures, high risk of recurrent bleeding because of overdose or delayed clearance of a drug, and the need for an urgent intervention associated with a high risk of bleeding [8].

Dabigatran has the longest half-life (12-17 h) of any of the DOACs $[6,9]$. The dabigatran concentration in the blood in the present patient was thought to be at a high level from the time of injury to the administration of idarucizumab, which likely resulted in the expansion of the intracranial hematoma. It has been recognized that trauma-associated coagulopathy is more common in patients with traumatic brain injury. The coagulopathy results in poor outcomes due to delayed or progressive bleeding and ischemic secondary injury [10-17].

\section{Conclusion}

We present a patient on dabigatran with acute intracranial hematoma who was successfully managed by administering idarucizumab preoperatively. We suggest that idarucizumab could be a potent therapeutic bridge to definitive surgical management in such traumatic brain injury patients taking dabigatran. This is an interesting case that demonstrated the use of idarucizumab in the emergency setting. As more patient populations are exposed to DOACs, reversal medications such as dabigatran may become more prevalent in the emergency department setting, making reports such as this important in laying the groundwork for further research.

\section{Abbreviations}

CT: Computed tomography; DOAC: Direct oral anticoagulants; GCS: Glasgow Coma Scale; POD: Postoperative day

Availability of data and materials

This case report only contains clinical data from medical records of the reported patient. The data will be made available upon request.

\section{Authors' contributions}

SM, KM, SK, HI, DW, and FS performed the treatment of the patient in the intensive care unit. $\mathrm{KH}$ performed the operation and treatment in the general ward. YN and YK helped to draft the manuscript. All authors read and approved the final manuscript.

Ethics approval and consent to participate Not applicable.

Consent for publication

We have written consent from the involved patient to present this case; the consent form will be provided upon request.

Competing interests

The authors declare that they have no competing interests. 


\section{Publisher's Note}

Springer Nature remains neutral with regard to jurisdictional claims in published maps and institutional affiliations.

\section{Author details}

'Department of Emergency and Critical Care Medicine, Kansai Medical University Medical Center, 10-15 Fumizono-cho, Moriguchi, Osaka 570-8507, Japan. ${ }^{2}$ Department of Emergency and Critical Care Medicine, Kansai Medical University Hospital, 2-3-1 Shinmachi, Hirakata, Osaka 573-1191, Japan.

\section{Received: 10 August 2018 Accepted: 24 September 2018}

Published online: 03 October 2018

\section{References}

1. Alalwan AA, Voils SA, Hartzema AG. Trends in utilization of warfarin and direct oral anticoagulants in older adult patients with atrial fibrillation. Am J Health Syst Pharm. 2017;74:1237-44.

2. Ashburner JM, Singer DE, Lubitz SA, Borowsky LH, Atlas SJ. Changes in use of anticoagulation in patients with atrial fibrillation within a primary care network associated with the introduction of direct oral anticoagulants. Am J Cardiol. 2017;120:786-91.

3. Ruff CT, Giugliano RP, Braunwald E, Hoffman EB, Deenadayalu N, Ezekowitz $M D$, et al. Comparison of the efficacy and safety of new oral anticoagulants with warfarin in patients with atrial fibrillation: a meta-analysis of randomised trials. Lancet. 2014;383:955-62.

4. Caldeira D, Rodriques FB, Barra M, Santos AT, de Abreu D, Gonçalves N, et al. Non-vitamin K antagonist oral anticoagulants and major bleeding-related fatality in patients with atrial fibrillation and venous thromboembolism: a systematic review and meta-analysis. Heart. 2015;101:1204-11.

5. Douketis JD, Healey JS, Brueckmann M, Fraessdorf M, Spyropoulos AC, Wallentin $L$, et al. Urgent surgery or procedures in patients taking dabigatran or warfarin: analysis of perioperative outcomes from the RE-LY trial. Thromb Res. 2016;139:77-81.

6. Feeney JM, Santone E, DiFiori M, Kis L, Jayaraman V, Montgomery SC. Compared to warfarin, direct oral anticoagulants are associated with lower mortality in patients with blunt traumatic intracranial hemorrhage: a TQIP study. J Trauma Acute Care Surg. 2016;81:843-8.

7. Zhang J, Jiang R, Liu L, Watkins T, Zhang F, Dong JF. Traumatic brain injuryassociated coagulopathy. J Neurotrauma. 2012;29:2597-605.

8. Levy JH, Ageno W, Chan NC, Crowther M, Verhamme P, Weitz Jl, et al. When and how to use antidotes for the reversal of direct oral anticoagulants: guidance from the SSC of the ISTH. J Thromb Haemost. 2016;14:623-7.

9. Gordon JL, Fabian TC, Lee MD, Dugdale M. Anticoagulant and antiplatelet medications encountered in emergency surgery patients: a review of reversal strategies. J Trauma Acute Care Surg. 2013;75:475-86.

10. Stein SC, Smith DH. Coagulopathy in traumatic brain injury. Neurocrit Care 2004; $1: 479-88$

11. Hulka F, Mullins RJ, Frank EH. Blunt brain injury activates the coagulation process. Arch Surg. 1996;131:923-7.

12. Harhangi BS, Kompanje EJ, Leebeek FW, Maas Al. Coagulation disorders after traumatic brain injury. Acta Neurochir. 2008;150:165-75.

13. Sun Y, Wang J, Wu X, Xi C, Gai Y, Liu H, et al. Validating the incidence of coagulopathy and disseminated intravascular coagulation in patients with traumatic brain injury--analysis of 242 cases. Br J Neurosurg. 2011;25:363-8.

14. Talving P, Benfield R, Hadjizacharia P, Inaba K, Chan LS, Demetriades D. Coagulopathy in severe traumatic brain injury: a prospective study. $J$ Trauma. 2009;66:55-61.

15. Franschman G, Boer $C$, Andriessen TM, van der Naalt J, Horn J, Haitsma l, et al. Multicenter evaluation of the course of coagulopathy in patients with isolated traumatic brain injury: relation to $\mathrm{CT}$ characteristics and outcome. J Neurotrauma. 2012;29:128-36.

16. Cap AP, Spinella PC. Severity of head injury is associated with increased risk of coagulopathy in combat casualties. J Trauma. 2011;71:S78-81.

17. Kim YJ. A systematic review of factors contributing to outcomes in patients with traumatic brain injury. J Clin Nurs. 2011;20:1518-32.

\section{Ready to submit your research? Choose BMC and benefit from:}

- fast, convenient online submission

- thorough peer review by experienced researchers in your field

- rapid publication on acceptance

- support for research data, including large and complex data types

- gold Open Access which fosters wider collaboration and increased citations

- maximum visibility for your research: over $100 \mathrm{M}$ website views per year

At $\mathrm{BMC}$, research is always in progress.

Learn more biomedcentral.com/submissions 